\title{
EVALUATION OF ONE-VISIT APEXIFICATION WITH MTA APICAL PLUG VERSUS TRADITIONAL CALCIUM HYDROXIDE APEXIFICATION WITH THE HELP OF PLATELET RICH FIBRIN APICAL MATRIX
}

\author{
Mohammed E Rokaya* and Elsaeed Abdel Hafiz ${ }^{* *}$
}

\begin{abstract}
This study aimed to evaluate one-visit apexification with MTA apical plug versus traditional calcium hydroxide apexification with the help of platelet rich fibrin (PRF) apical matrix. Methods: 18 immature permanent maxillary anterior teeth with non-vital pulp were chosen from 14 children ranging from 9 to 15 years old, and were divided randomly into two main groups with 9 teeth in each group [Group I MTA, and Group $2 \mathrm{Ca}(\mathrm{OH})_{2}$ ]. Platelet Rich Fibrin was used for both groups as internal apical matrix. In group 1 MTA approximately 4-5 mm thickness of mixed MTA apical plug was placed at the apical end of the root, then the canal was obturated by Obtura II system after 24 hours, while in group $2 \mathbf{C a}(\mathbf{O H})_{2}$; the apexification was done by $\mathrm{Ca}(\mathrm{OH})_{2}$ and renewed at 3,6 months and after 12 months the canal was obturated by Obtura II system. The radiographs were taken for all cases at preoperatively, post operatively and at 3,6 and 12 months follow up. Data were subjected to statistically analyze. Results: At 12 months follow up period $100 \%$ of teeth with calcific apical barrier were detected in Group 1 MTA, and $88 \%$ of teeth with calcific apical barrier were detected in Group 2 Ca $(\mathbf{O H})_{2}$. However, there was no difference in statistically point of view between the groups. Conclusions: One-visit apexification provides an alternative treatment option over the traditional calcium hydroxide apexification in treating the non-vital cases with open apices.
\end{abstract}

\section{INTRODUCTION}

Traumatic dental injuries to the teeth are most common during young ages ${ }^{(1)}$. The majority of these injuries occur before the completion of the $\operatorname{root}^{(2)}$. Premature loss of vital pulp results in an open $\operatorname{apex}^{(3)}$.
The management of dead tooth with open apex composed of the induction of a natural or artificial apical barrier that can act as a stop for the obturating material, and this is called apexification, which is defined as a method to induce a calcified barrier in a root with an open apex or the continued apical development of an incomplete root in dead teeth ${ }^{(4)}$.

* Lecturer of Endodontics, Faculty of Dental Medicine, Al-Azhar University (Assuit Branch) - Egypt.

** Lecturer of Endodontics, Faculty of oral and Dental Medicine, Future University, Cairo, Egypt. 
Much material has been used to initiate the hard tissue barrier as calcium hydroxide, Mineral Trioxide Aggregate (MTA), Biodentine, Endosequence. Calcium hydroxide has been commonly used as medicament to induce hard tissue formation in open apices. The Calcium hydroxide is refreshed periodically till an apical barrier is achieved. Time needed to form an apical barrier is usually ranging from 6 to 18 months and depends upon size of apical foramen, presence of infection ${ }^{(5)}$.

MTA was developed by Torabinejad. It was used as a root-end filling material ${ }^{(6)}$. It is consists of dicalcium silicate, tricalcium silicate, tricalcium aluminate, gypsum, tetracalcium aluminoferrite and bismuth oxide. Setting time of grey MTA differs with manufacturers, for ProRoot MTA it was reported to be $2 \mathrm{~h}$ and $45 \mathrm{~min}$ ( $\pm 5 \mathrm{~min}$ ) and MTAAngelus it was $10 \mathrm{~min}{ }^{(7)}$.

MTA has low solubility and a radiopacity. It also demonstrated an excellent biocompatibility and sealing ability ${ }^{(8)}$. Antimicrobial properties of MTA were related to its $\mathrm{pH}$, it has a $\mathrm{pH}$ of 12.5 comparable to that of calcium hydroxide ${ }^{(9)}$.

MTA appears to be more predictable with consistent hard-tissue formation than $\mathrm{Ca}(\mathrm{OH})_{2}$. In using MTA for apexification, it will reduce the treatment time and the produces gives more good results. One-visit apexification technique with MTA offers major advantage over traditional calcium hydroxide methods ${ }^{(10)}$.

The basis is to create an apical barrier that would facilitate the root canal to be filled at once ${ }^{(11)}$.

Another major problem in cases of a wide open apex is the need to limit the apexification material at the apex, thus avoiding the extrusion of a large amount of material into the periodontal tissue. The use of a matrix is advisable since its placement in the area of bone destruction provides a base on which the sealing material, can be packed in the perforation ${ }^{(12)}$. A lot of materials have recommended to be used as a matrix in perforations as the teeth with incomplete formation of apex. These materials include $\mathrm{Ca}(\mathrm{OH})_{2}$, hydroxyapatite, absorbable collagen, and calcium sulphate $^{(13,14)}$.

So this study was directed to evaluate onevisit apexification with MTA apical plug versus traditional calcium hydroxide apexification with the help of platelet rich fibrin (PRF) apical matrix.

\section{MATERIALS AND METHODS}

\section{Selection of cases in the study}

A total of 18 immature permanent maxillary anterior teeth with non-vital pulp, were chosen from 14 children ranging between $(9-15)$ years old, were enrolled in this study. The patients were selected from the outpatient clinic of endodontic department, faculty of dental medicine, Al-Azhar University (Assuit branch).

Complete medical and dental history was obtained, clinical and radiographic examination was recorded in a diagnostic sheet for every case included in the study.

Radiographic examination included a periapical radiograph with film holder using the parallel technique and a size 2 film (Kodak; Carestream Health Inc., Rochester, NY, USA) at exposure 70 $\mathrm{Kvp}, 8 \mathrm{Ma}$ for $0.04 \mathrm{~s}$. At least 1 preoperative digital radiograph was taken, more if necessary, to visualize the radiographic status of the periradicular tissues if a radiolucent area is present, no internal or external root resorption.

\section{Cases classification}

The selected 18 teeth were divided randomly into two main groups with (9 each):

\section{Group I (MTA group)}

Apexification was performed with MTAAngelus (ANGELUS, Brazil) as apical plug. 


\section{Group II (calcium hydroxide group)}

Apexification was performed with calcium hydroxide (U.S.P Sultan Health care) powder mixed with distilled water.

\section{Treatment procedures}

- All treatment procedures were performed with local anesthesia and rubber dam application.

- The coronal cavity was prepared with a round bur and Endo Z bur (DENTSPLY Maillefer, Tulsa Dental products, Tulsa, OKLA, USA) in a high speed headpiece (PANA AIR, NSK, Japan).

- The working length was measured from the preoperative radiograph and confirmed by taking a radiograph with a $\mathrm{k}$ file (Mani japans files) inserted into the root canal within $1 \mathrm{~mm}$ of the radiographic apex.

- No mechanical preparation was done because of thin radicular dentin and open apex. So the walls were smoothened only by circumferential filing using $\mathrm{H}$ - file (1 $\mathrm{mm}$ short of apex).

- The root canals were passively irrigated with alternation between $5 \mathrm{ml}$ of $2.6 \% \mathrm{NaOCL}$ solution (Prime Dental Products Pvt. Ltd. India) after each file and 17\%EDTA gel (DENTSPLY Tulsa Dental), final rinse was done with $5 \mathrm{ml}$ distilled water. Delivery of the irrigants was performed by Max- I- probe irrigating syringe (DENTSPLY Maillefer, USA) $2 \mathrm{~mm}$ shorter of the working after each file.

- $\quad$ The canal was dried with paper point size 80 . Then the disinfection of the root canals were done by using double antibiotic paste (DAP) was used as an intracanal medicament for 2 weeks (Ciprofloxacin 200mg, Metronedazole $500 \mathrm{mg}$ ) was used for all groups. A sterile cotton pellet was placed in the orifice and the coronal cavity was sealed with ketac-fil filling material (3M, ESPE, Aplicap, Ketac,Maxicap, Canada).
- All the cases were reviewed after two weeks following initial placement of double antibiotic paste. The rubber dam was applied then ketacfil and double antibiotic paste were removed by rinsing the canal with $5 \mathrm{ml}$ of $2.6 \% \mathrm{NaOCl}$ over a 1 minute period with intermittent circumferential filing with a size $80 \mathrm{H}$-file which introduced $1 \mathrm{~mm}$ short of the working length. Irrigation was repeated until the solution became clear from any medicament residue. A final rinse was performed with distilled water then paper point size 80 was used to dry the canal.

\section{Preparation of internal matrix}

Ten milliliters of patient's venous blood was collected in BD Vacutainer ${ }^{\circledR}$ blood collection tube (Belliver Industrial Estate, Plymouth, PL6 7BP, UK) without anticoagulant and immediately centrifuged (Process ${ }^{\circledR}$ centrifuge PC-02; Process Ltd., Nice, France) at 3000 rpm for 15 minutes ${ }^{(15)}$. After centrifugation there will be of three layers a base of red blood corpuscles (RBCs) at the bottom, acellular plasma on the surface, and PRF (Platelet Rich Fibrin) clot in the middle (Fig. 1).

The fibrin clot separated from the lowest layer of the centrifugation product. The PRF clot was gently pressed into a membrane form with sterile moist gauze and placed on a sterile glass slab to be used.

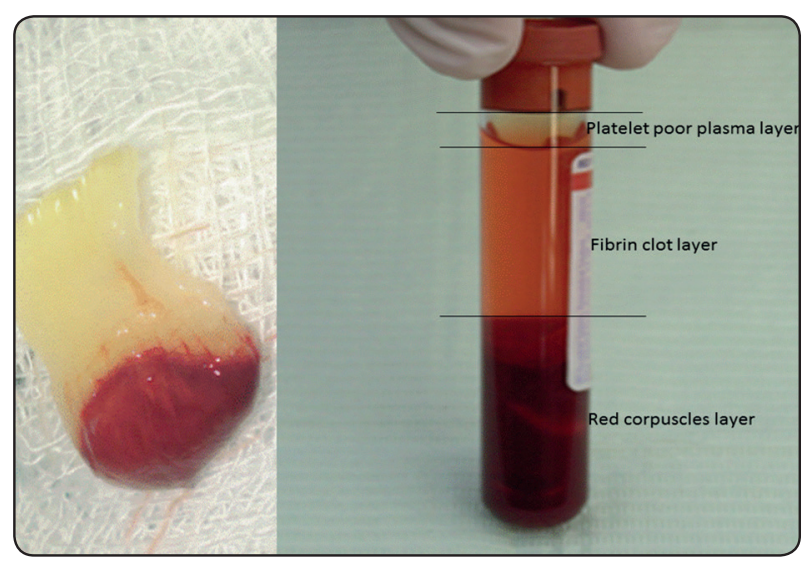

Fig. (1) A photograph showing the three layers of centrifuged blood. 
The required quantity of PRF membrane was introduced into the canal and positioned apically with premeasured suitable size hand schilder plugged (DENTSPLY Maillefer - USA) at the apical foramen into the bony space beyond it.

\section{Group I (MTA group)}

Apexification was performed with MTA as apical plug. Angelus MTA was mixed according to the manufacturer's instruction. The mixed MTA inserted to the apical one third of the prepared canal by using Micro Apical placement system MAP (DENTSPLY,Tulsa.USA) and condensed with premeasured schilder pluggers until approximately 4-5 $\mathrm{mm}$ thickness of mixed MTA was placed at the apical end of the root. The correct placement,extension and quality of MTA apical plug was assessed with radiograph (Fig. 2).

A moist cotton pellet was placed over the material and the access cavity was sealed with ketac-fil filling. After 24 hours the set of the MTA was checked with $\mathrm{K}$ file and final obturation of the root canal was done by thermo plasticized injectable gutta-percha by Obtura II system (Fenton Business

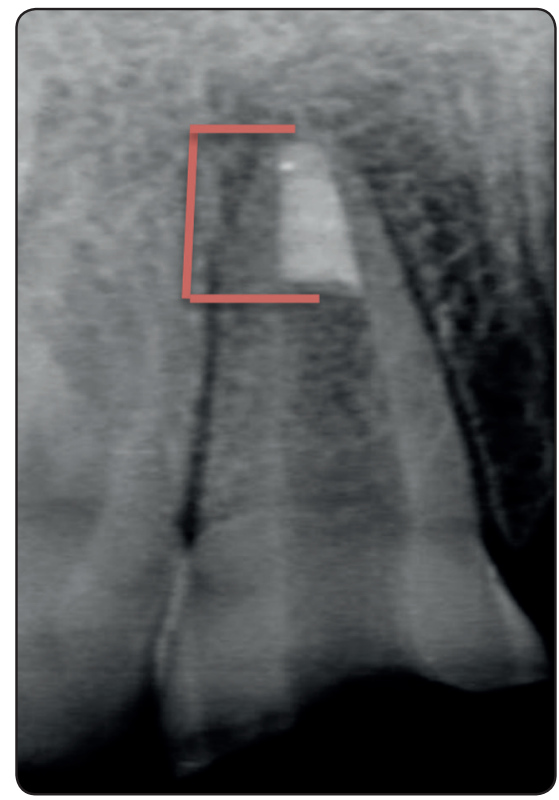

Fig. (2): A Photograph showing extends of the MTA apical plug.
Pk Fenton, Mo 63026, USA) with AH Plus Root canal sealer (Dentsply Detrey, GmbH, 78467, Konstanz, Germany).

The access cavity was then sealed with the composite restoration (Filtek Z 350 3M ESPE, St. Paul, MN 55144-1000 USA).

\section{Group II (calcium hydroxide group)}

Apexification was performed with calcium hydroxide. Insertion of calcium hydroxide dressing into prepared canal was performed by using amalgam carrier. A plug of calcium hydroxide dressing was deposited in the canal and condensed without pressure exerted on the canal wall to the apical end of the root with premeasured suitable size schilder plugger. Other applications of calcium hydroxide were realized, until complete canal filling was accomplished, and radiographically confirmed. The access cavity was then sealed with the composite restoration Filtek Z 350.

The progress of barrier formation was examined 3 months after the first placement of calcium hydroxide dressing and at 6 and 12 months thereafter.

At each follow-up appointment the calcium hydroxide dressing was removed by flushing the canal with $5 \mathrm{ml}$ of $2.6 \% \mathrm{NaOCL}$. The clinical detection of an apical barrier was determined by gently probing the apical region with a $25 \mathrm{~K}$ file circumferentially. Apical closure was confirmed if the file could not be placed beyond the working length. If an apical barrier had not been formed, refilling the canal with new mix of calcium hydroxide dressing was repeated until the presence of an apical barrier was detected.

Radiographic verification of an apical stop was considered positive when there was evidence of a normal periodontal space, a decrease in size of the periapical lesion if present compared with pre-operative radiographs and no evidence of inflammatory external resorption. 
Obturation of the root canal was done by thermo plasticized injectable gutta-percha by Obtura II system with AH Plus Root canal sealer. The access cavity was then sealed with the composite restoration Filtek Z 350.

\section{Radiographic imaging of the groups}

All the radiographic evaluation was achieved by an indirect digital image radiographic system. The plate was read through the Durr Vista Scan Perio workstation (Durr Dental, Bietigheim-Bissingen, Germany) Fig 3A. Images were analyzed by the software Durr DBSWIN 5.11.0 (Fig 3B) with no image enhancement. Standardized intra oral periapical digital image for each of selected tooth were made before treatment, immediate post treatment and at each recall visit using standardized paralleling technique with XCP film holder (Dentsply Sirona USA). The image plate of indirect digital radiographic was mounted to periapical film holder then inserted in the patient's mouth and assembled to the plastic aiming ring at the end of long cone of the $x$ ray tube. The image plate was exposed by the $\mathrm{x}$-ray machine of fixed exposure (70 KVP, 8Ma for $0.04 \mathrm{~s}$ ) for all patients during the whole follow up periods.

\section{Radiographic evaluation criteria}

The radiographs were taken for all cases at the end of the treatment after final restoration, and then at 3,6 and 12 months post treatment. The radiographs were exposed by the $\mathrm{x}$ ray machine at $70 \mathrm{KVP}, 8 \mathrm{Ma}$ for $0.04 \mathrm{~s}$. The exposure parameters were fixed for the entire patient during the whole follow up period. At each recall visit, each tooth assessed radiographically for the following:

A) Presence or absence of calcified apical barrier.

B) Fate of periapical radiolucency if it was present at the baseline.

C) Radiographic success rate.

Densitometric radiographic measurement for the assessment of healing of periapical rdiolucencies were performed by drawing an imaginary circle coinciding with periapical rdiolucencies at the apex of selected tooth (Fig.4 ,5). The diameter of the drawn circle is recorded in $\mathrm{mm}$. The gray level along the diameter was recorded $(1 \mathrm{~mm})$ from the beginning of the line, at the middle and $1 \mathrm{~mm}$ from the end of the line. The average of the three readings was calculated to obtain the mean average of the gray level .along the diameter

\section{Statistical Analyses}

The collected data obtained were registered, tabulated and presented as mean value, standard deviation (SD), frequencies and Percentages. Data explored for normality using Kolmogorov-Smirnov and Shapiro-Wilk tests. One Way analysis of variance (ANOVA) used to compare between tested groups flowed by Tuckey post-hoc test for pairwise comparisons.

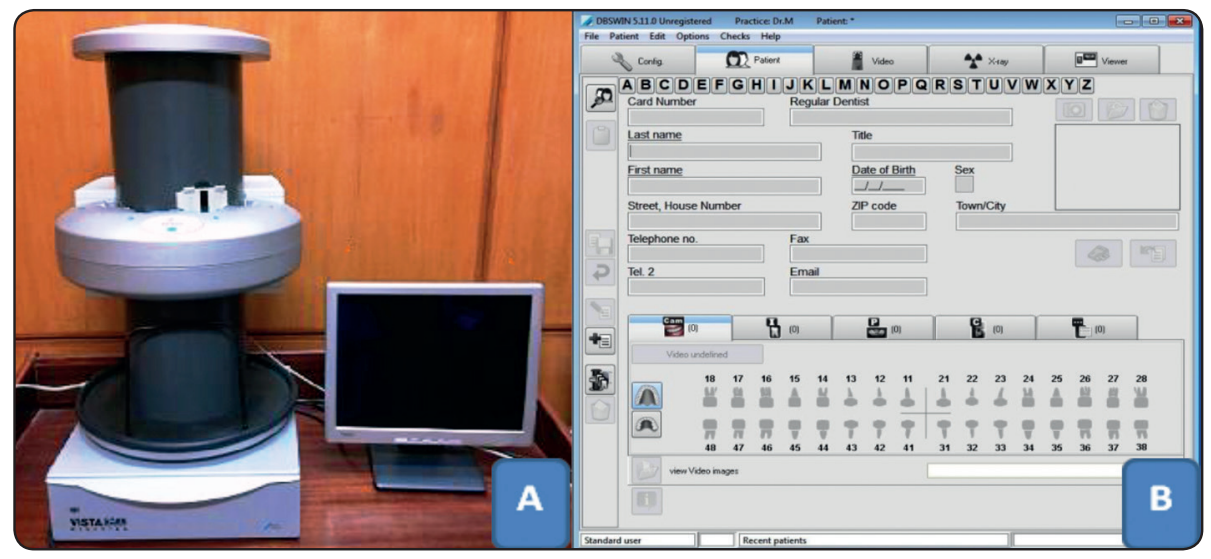

Fig. (3): Photograph showing: (A) Digital X-ray Durr Vista Scan system, and (B) Patient card in DBSWIN 5.11.0 software system. 


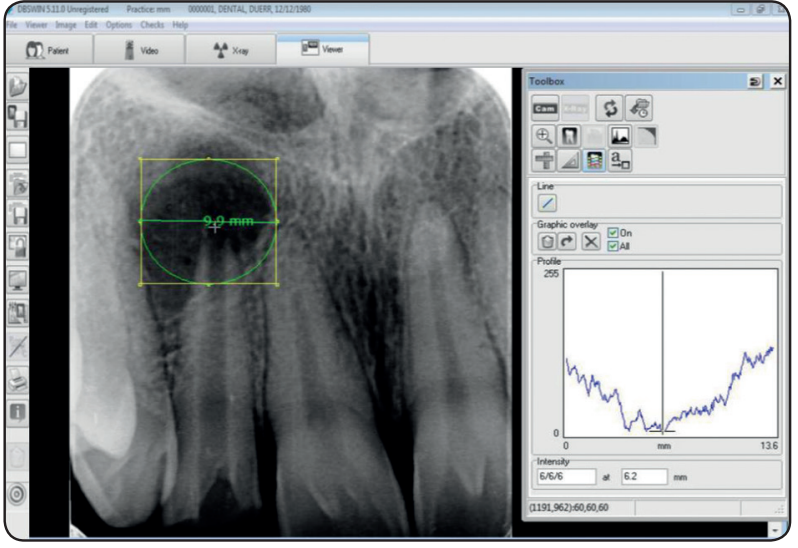

Fig. (4): Photograph showing bone density measurement at the baseline.

\section{RESULTS}

\section{Radiographic evaluation}

Table 1, and Figure 6 showed The Frequencies $(\mathrm{N})$ and Percentages (\%) of radiographic parameters for the both groups along preoperative, postoperative, 3,6,12 months follow up periods.

\section{A) Periapical Radiolucency}

Analysis of the pre-operative and post-operative data revealed that periapical radiolucency was present in 55\% of teeth in Group 1 MTA, and 45\% of teeth in Group $2 \mathrm{Ca}(\mathbf{O H})_{2}$.

After 3 months follow up period percentages of teeth with periapical radiolucency reduced to $22 \%$ for both groups.

While complete healing of teeth with periapical radiolucency was seen in both groups after 6 months. However, Kruskal Wallis test showed that there was no statistically significant difference between the two groups $(\mathrm{p} \leq 0.05)$.

\section{B) Calcific Apical Barrier Formation}

After 3 months follow up period higher percentage of teeth $77 \%$ with calcific apical barrier were detected in Group 1 MTA. None of the teeth in Group $2 \mathbf{C a}(\mathbf{O H})_{2}$ showed any calcific apical barrier. There was statistically significant between

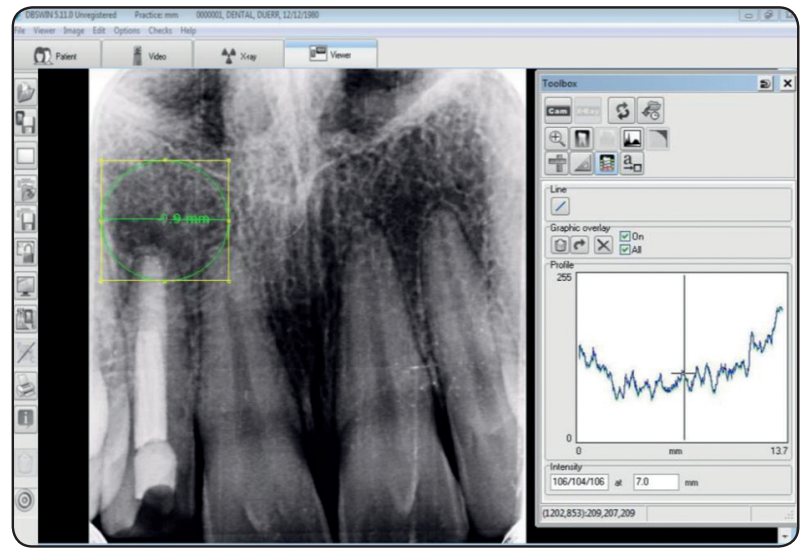

Fig. (5): Photograph showing bone density measurement after 12 months.

the two groups $(\mathrm{p} \leq 0.05)$.

After 6 months follow up period 100\% of teeth with calcific apical barrier were detected in Group 1 MTA, and 74\% of teeth with calcific apical barrier were detected in Group $2 \mathbf{C a}(\mathbf{O H})_{2}$. However, there was no statistically significant difference between the two groups $(\mathrm{p}=0.250)$.

At 12 months follow up period $100 \%$ of teeth with calcific apical barrier were detected in Group 1 MTA, and $88 \%$ of teeth with calcific apical barrier were detected in Group 2 Ca $(\mathbf{O H})_{2}$. However, there was no statistically significant difference between the two groups $(\mathrm{p}=0.300)$.

\section{C) Radiographic success rate}

Frequencies (N) and Percentages (\%) of radiographic success and failure rate of different subgroups at the final follow up period (12 months) were listed in table (2) and figure (7).

Analysis of the data revealed that the radiographic success rate was 100\% in Group 1 MTA as all teeth revealed calcific barrier formation, with no evidence of radiographic pathology. But the radiographic success rate was $88 \%$ in Group $2 \mathbf{C a}(\mathbf{O H})_{2}$ as one tooth scored absence of calcific apical barrier. However, the difference between the groups was not statistically significant. 
TABLE (1): Frequencies (N), Percentages (\%) and p-value of radiographic parameters in the two groups along different follow-up periods.

\begin{tabular}{|c|c|c|c|c|c|c|c|}
\hline & & & & $\begin{array}{l}\text { up } 1 \\
\text { TA }\end{array}$ & & $\begin{array}{l}\text { lp } 2 \\
\mathrm{OH})_{2}\end{array}$ & 1 \\
\hline & & & $\mathrm{N}$ & $\%$ & $\mathrm{~N}$ & $\%$ & P-value \\
\hline & & Yes & 5 & $55 \%$ & 4 & $45 \%$ & \\
\hline 苞 & 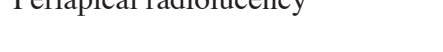 & No & 4 & $45 \%$ & 5 & $55 \%$ & 0.90 \\
\hline 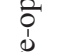 & & Present & 0 & $0 \%$ & 0 & $0 \%$ & \\
\hline & Calcined apical Darrier Iormation & Not present & 9 & $100 \%$ & 9 & $100 \%$ & 1.00 \\
\hline$\stackrel{0}{>}$ & & Yes & 5 & $55 \%$ & 4 & $45 \%$ & \\
\hline 苞 & remapical ranorucenicy & No & 4 & $45 \%$ & 5 & $55 \%$ & 0.901 \\
\hline$\overline{1}$ & & Present & 0 & $0 \%$ & 0 & $0 \%$ & \\
\hline & Calcified apical barrier formation & Not present & 9 & $100 \%$ & 9 & $100 \%$ & 1.00 \\
\hline & D. . & Yes & 2 & $22 \%$ & 2 & $22 \%$ & \\
\hline$\stackrel{\mathscr{E}}{E}$ & Periapical radiolucency & No & 7 & $78 \%$ & 7 & $78 \%$ & 0.053 \\
\hline$\underset{\Xi}{\Xi}$ & Col if & Present & 7 & $77 \%$ & 0 & $0 \%$ & $0001 *$ \\
\hline & Calcinteu apical valn & Not present & 2 & $23 \%$ & 9 & $100 \%$ & 0.001 \\
\hline & Porionicol rodioluconcu & Yes & 0 & $0 \%$ & 0 & $0 \%$ & 100 \\
\hline$\stackrel{\text { E }}{E}$ & Perrapical radorocency & No & 9 & $100 \%$ & 9 & $100 \%$ & 1.00 \\
\hline$\underset{\Xi}{\Xi}$ & Colcifod anicl harrior formation & Present & 9 & $100 \%$ & 6 & $74 \%$ & 0250 \\
\hline & Calcinted applcal Dartrer formation & Not present & 0 & $0 \%$ & 3 & $26 \%$ & 0.250 \\
\hline & Perianical radiolucency & Yes & 0 & $0 \%$ & 0 & $0 \%$ & 100 \\
\hline 节 & Periapical radioiucency & No & 9 & $100 \%$ & 9 & $100 \%$ & 1.00 \\
\hline$\underset{\Xi}{\mathcal{I}}$ & 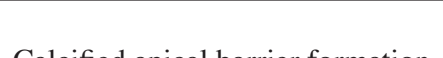 & Present & 9 & $100 \%$ & 8 & $88 \%$ & 200 \\
\hline & Calcined apical barrier formation & Not present & 0 & $0 \%$ & 1 & $12 \%$ & 0.300 \\
\hline
\end{tabular}

*Significant at $p \leq 0.05$

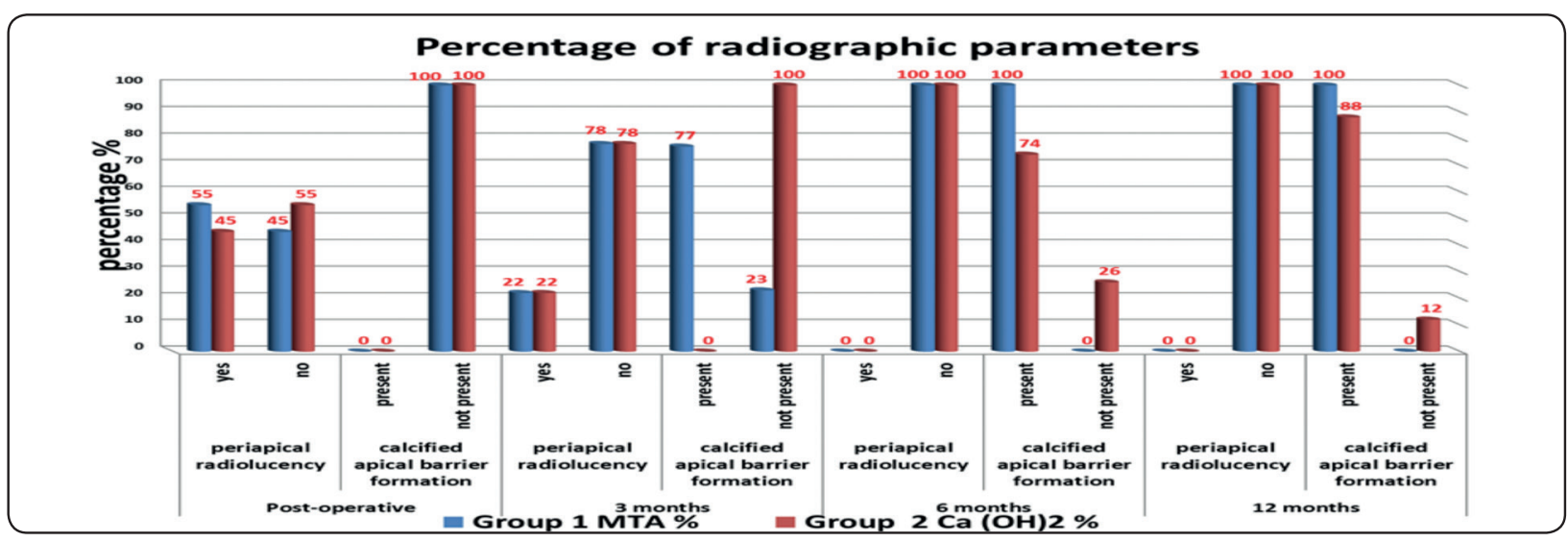

Fig (6): Histogram showing the percentage of radiographic parameters in the two groups along different follow-up periods. 
TABLE (2): Frequencies (N), Percentages (\%) and p-value of radiographic success and failure of the tested groups.

\begin{tabular}{|c|c|c|c|c|c|c|}
\hline & & \multicolumn{4}{|c|}{ Groups } & \multirow{3}{*}{ P-value } \\
\hline & & \multicolumn{2}{|c|}{$\begin{array}{c}\text { Group } 1 \\
\text { (MTA) }\end{array}$} & \multicolumn{2}{|c|}{$\begin{array}{l}\text { Group } 2 \\
\mathrm{Ca}(\mathrm{OH})_{2}\end{array}$} & \\
\hline & & $\mathrm{N}$ & $\%$ & $\mathrm{~N}$ & $\%$ & \\
\hline \multirow{2}{*}{ 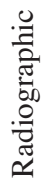 } & Success & 8 & $88 \%$ & 9 & $100 \%$ & \multirow{2}{*}{0.289} \\
\hline & Failure & 1 & $12 \%$ & 0 & $0 \%$ & \\
\hline
\end{tabular}

*Significant at $p \leq 0.05$.

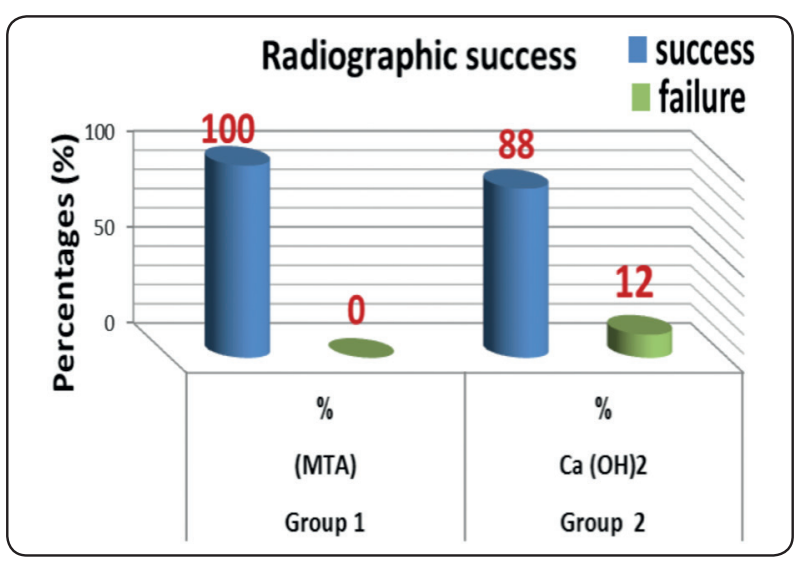

Fig (7): Histogram showing the percentage of radiographic success in two groups.

\section{DISCUSSION}

The goal of apexification is to gain apical barrier in order to avoid the extrusion of the obturating material. Though the disadvantage of implementing calcium hydroxide is the time consumed for the completing the procedures which can range cover from 3 to 54 months.

The Other side effect of calcium hydroxide is that the tooth with calcium hydroxide placed for more than 100 days showed a significant reduction in fracture resistance ${ }^{(16)}$.

The Patient also may fail to return for scheduled visits, and the temporary seal may fail resulting in reinfection or failure of treatment. For these reasons one-visit apexification has been suggested. Some authors defined the one-visit apexification technique as the non-surgical manipulation of a biocompatible material into the apical end of the root canal to establish an apical stop that would enable the root canal to be filled immediately ${ }^{(17)}$.

Revascularization considered as a good alternative treatment option for these types of cases. But, there are no randomized controlled clinical trials available till now for the success of these procedures on teeth with persistent periapical infection $^{(18)}$.

Upon these considerations, the present study was aimed to evaluate one-visit apexification with MTA apical plug versus traditional calcium hydroxide apexification by Vistascan system and the help of Platelet Rich Fibrin as an apical matrix.

Disinfection of the root canals were done by using double antibiotic paste (DAP) was used as an intracanal medicament for 2 weeks instead of triple antibiotic paste. Double antibiotic paste was used because Minocycline in Triple Antibiotic Paste (TAP) causes discoloration of tooth structure and many studies showed that effect of both TAP and DAP is the same ${ }^{(19)}$.

In the present study the Platelet-rich fibrin (PRF) membrane was used as internal apical matrix to avoid the extrusion of the MTA or the calcium hydroxide apically, and has advantages of low cost, ease of procedure, does not dissolve quickly after application, and is biocompatible. The success of this technique depends entirely on the speed of blood collection and transfer to the centrifuge, if prolonged failure will occur ${ }^{(15)}$.

A $5 \mathrm{~mm}$ thick apical MTA barrier has proven to be significantly stronger with lesser leakage than a $2 \mathrm{~mm}$ thick barrier ${ }^{(20)}$. In the present approximately 4-5 mm thickness of mixed MTA was placed at the apical end of the root canal in group 1 (MTA). 
The teeth in both groups were assessed according to radiographic parameters (presence or absence of periapical radiolucency, and calcific apical barrier formation) with Vista Scan system for each tooth preoperatively, post operatively and at 3,6 and 12 months follow up.

The presence or absence of Periapical lesions was assessed at the base line and during different follow up examination to appraise any difference in the healing tendency between the two groups.

The results of this study revealed that of the pre-operative and post-operative data recorded that periapical radiolucency was present in $55 \%$ of teeth in Group 1 MTA, and 45\% of teeth in Group $2 \mathrm{Ca}(\mathrm{OH})_{2}$. But after 3 months follow up period percentages of teeth with periapical radiolucency reduced to $22 \%$ for both groups. While complete healing of teeth with periapical radiolucency was seen in both groups after 6 months without statistically significant difference between the two groups $(\mathrm{p} \leq 0.05)$.

This indicates that the presence of Periapical lesions at the baseline doesn't negatively affect the radiographic outcome this is in agreement with Holden et al. ${ }^{(21)}$ and Nayar et al ${ }^{(22)}$. But on the other side Cvek ${ }^{(23)}$ has reported that the presence of a periapical radiolucency at the start of treatment increases the time required for barrier formation.

The results of Calcific Apical Barrier Formation showed that After 3 months follow up period higher percentage of teeth $77 \%$ with calcific apical barrier were detected in Group 1 MTA. None of the teeth in Group $2 \mathrm{Ca}(\mathrm{OH})_{2}$ showed any calcific apical barrier. There was statistically significant between the two groups $(\mathrm{p} \leq 0.05)$.

But after 6 months follow up period 100\% of teeth with calcific apical barrier were detected in Group 1 MTA, and $74 \%$ of teeth with calcific apical barrier were detected in Group $2 \mathrm{Ca}(\mathrm{OH})_{2}$. On other hand At 12 months follow up period $100 \%$ of teeth with calcific apical barrier were detected in Group 1 MTA, and $88 \%$ of teeth with calcific apical barrier were detected in Group $2 \mathrm{Ca}(\mathrm{OH})_{2}$. However, there was no statistically significant difference between the two groups after 6 , and 12 months.

This may be due to MTA provides scaffolding for the formation of hard tissue and the potential of a better biological seal as described by Witherspoon and Ham ${ }^{(24)}$. Its high $\mathrm{pH}$ helps to destroy the surrounding microorganisms and its bioactive nature stimulates the cells to create favorable environment for healing. It also promotes cementum deposition on it ${ }^{(20)}$.

Analysis of the data of the present study revealed that the radiographic success rate was $100 \%$ in Group 1 MTA as all teeth revealed calcific barrier formation, with no evidence of radiographic pathology. But the radiographic success rate was $88 \%$ in Group $2 \mathrm{Ca}(\mathrm{OH})_{2}$ as one tooth scored absence of calcific apical barrier.

These percentage results were in accordance with the results of Meligy and Avery (25) who reported $100 \%$ clinical and radiographic success rate for MTA and $87 \%$ for $\mathrm{Ca}(\mathrm{OH}) 2$. Damle et at. ${ }^{(26)}$ reported $90.09 \%$ clinical and radiographic success rate for MTA and $81.81 \%$ for $\mathrm{Ca}(\mathrm{OH}) 2$.

A review of 10 studies, which examined by Sheehy and Roberts ${ }^{(27)}$ and they reported that the use of calcium hydroxide for apical barrier formation was successful in $74-100 \%$ of cases irrespective of the proprietary brand used.

\section{CONCLUSIONS}

One-visit apexification provides an alternative treatment option over the traditional calcium hydroxide apexification in treating the non-vital cases with open apices. 


\section{REFERENCES}

1. Andreasen JO, Andreasen FM. Textbook and color atlas of traumatic injuries to the teeth, $3^{\text {rd }}$ edn. Copenhagen: Munkasgaard 1994.

2. Moore A, Howley MF, O'Connell AC. Treatment of open apex teeth using two types of white mineral trioxide aggregate after initial dressing with calcium hydroxide in children. Dent Traumatol 2011 Jun; 27(3):166-73.

3. Ahlawat B, Kumar A, Chaudhary N, Vijaylaxmy, Bhardwaj V. Apexification with Rapid MTA Plug Technique. Indian J.Sci. Res 2015; 6(2):153-6.

4. American Association of Endodontists. Glossary of endodontic terms, 7th edn. Chicago; 2003.

5. Sheehy EC, Robertts GJ. Use of calcium hydroxide for apical barrier formation and healing in non-vital immature permanent teeth: a review, Br Dent 1997; 183(7): 241-46.

6. Torabinejad M, Hong CU, McDonald F, Pitt Ford TR. Physical and chemical properties of a new root-end filling material. J Endod 1995; 21: 349-53.

7. Srinivasan V, Waterhouse P, Whitworth P. Mineral trioxide aggregate in pediatric dentistry. Int $\mathrm{J}$ of Paed Dent 2009; 19: 34-47.

8. Rafter M. Apexification: a review. Dent Traumatol 2005; 21: 1-8.

9. Torabinejad M, Hong CU, Pitt Ford TR, Kettering JD. Antibacterial effects of some root-end filling materials. J Endod 1995; 21:403-6.

10. Huang G.T.-J. Apexification: the beginning of its end. International Endodontic Journal 2009; 42:855-66.

11. Morse DR, O'Larnic J, Yesilsoy C. Apexification: review of the literature. Quintessence Int 1990; 21:589-98.

12. Lemon RR. Nonsurgical repair of perforation defects. Internal matrix concept. Dent Clin North Am. 1992; 36:439-457.

13. Bargholz C. Perforation repair with mineral trioxide aggregate: a modified matrix concept. Int Endod J.2005; 38:59-69.

14. Al-Daafas A, Al-Nazhan S. Histological evaluation of contaminated furcal perforation in dogs' teeth repaired by MTA with or without internal matrix. Oral Surg Oral Med Oral Pathol Oral Radiol Endod. 2007; 103:92-99.

15. Pawar RB, Margsahayam SV, Shenoy VU, Shaikh SAH. Management of a Traumatized Open Apex Tooth with a
Combination of Mineral Trioxide Aggregate Apical Plug and Platelet-rich Fibrin Apical Matrix. J Contemp Dent 2016;6(1):57-62.

16. Haque Farzana, Ahmed Zubaer, Akter Shamme Rime, Hossain Mossharaf, Chowdhury Almas, Khan Mohammad. An Overview of Mineral Trioxide Aggregate in Apexification. Journal of Advances in Medicine and Medical Research 2017; 22(11): 1-7.

17. Rafter M. Apexification: a review. Dent Traumatol 2005; 21: $1-8$.

18. Geisler TM. Clinical considerations for regenerative endodontic procedure. DCNA 2012 Jul; 56(3):603-626.

19. Alaa H.A. Sabrah Evaluation of Residual Antibacterial Effect of Human Radicular Dentin Treated with Triple and Double Antibiotic Pastes. JOE 2015; 41(7):1081- 84.

20. Seal M, Talukdar P, Pendharkar K, Bhattacharyya A. Treatment of an Open Apex with One-visit Apexification using Mineral Trioxide Aggregate. Int J Oral Care Res 2016; 4(2):142-145.

21. Holden WT, Schwartz SA, Kirkpatrick TC. Clinical outcomes of artificial root-end barriers with mineral trioxide. J Endod 2008; 34: 812-817.

22. Nayar S, Bishop K, Alani A. A report on the clinical and radiographic outcomes of 38 cases of apexification with mineral trioxide aggregate. Eur J Prosth odont Restor Dent 2009; 17(4):150-156.

23. Cvek M. Treatment of non-vital permanent incisors with calcium hydroxide. I. Follow-up of periapical repair and apical closure of immature roots. Odonotol Revy 1972; 23:27- 44 .

24. Witherspoon DE, Ham K. One-visit apexification: Technique for inducing root end barrier formation in apical closures. Pract Proced Aesthet Dent. 2001; 13(6): 455-60.

25. El-Meligy OA, Avery DR. Comparison of apexification with mineral trioxide aggregate and calcium hydroxide. Pediatr Dent 2006; 28:248-53.

26. Damle SG, Bhattal H, Damle D, Dhindsa A, Loomba A, Singla S. Clinical and radiographic assessment of mineral trioxide aggregate and calcium hydroxide as apexification agents in traumatized young permanent anterior teeth: A comparative study. Dent Res J 2016; 13:284-91.

27. Sheehy EC, Roberts GJ. Use of calcium hydroxide for apical barrier formation and healing in non-vital immature permanent teeth: a review. Br Dent J 1997; 183:241- 6 . 